\title{
Analyticity and Systematicity Students of Mathematics Education on Solving Non-routine Problems
}

\author{
Swasti Maharani ${ }^{1,2, *}$, Toto Nusantara ${ }^{1}$, Abdur Rahman As'ari ${ }^{1}$, Abdul Qohar ${ }^{1}$ \\ ${ }^{1}$ Department of Postgraduate Mathematics Education, Universitas Negeri Malang, Indonesia \\ ${ }^{2}$ Department of Mathematics Education, Universitas PGRI Madiun, Indonesia
}

Copyright $(2019$ by authors, all rights reserved. Authors agree that this article remains permanently open access under the terms of the Creative Commons Attribution License 4.0 International License

\begin{abstract}
Critical thinking is a skill needed for education. Critical thinking has two main components i.e. ability and critical thinking disposition. The purpose of this research is to describe the disposition of critical thinking of mathematics education students especially analyticity and systematicity component when solving non-routine problem (the problem that is not logical and incomplete). This research is a qualitative descriptive study. The stages in this study are first, students are given three non-routine questions. The second stage, the researchers observed directly and recorded the subject when working on the problem. Third, interviewing the subject related to non-routine problem resolution. Fourth, concluded by describing the disposition of critical thinking of mathematics teacher candidate students, especially analyticity and systematicity components. The results showed that the disposition of critical thinking of first-year college students in mathematics education major is still low. They have not analyzed the problems and answers well and have not written the answers in order and lack of focus when solving non-routine problems. They not yet have a high sense about the irregularities of the problem. It is highly recommended for further research that there is a need for advanced development to improve the disposition of critical thinking students.
\end{abstract}

Keywords Critical Thinking Disposition, Analyticity, Systematicity, Non-routine Problems

\section{Introduction}

Technological advances such as the internet make information very accessible to everyone. The ease of access to information is growing very rapidly. However, it does not ensure the ability to use the knowledge astutely to facilitate problem solving. In dealing with these developments, critical thinking is needed in order not to get caught in the negative flow of globalization. Educators and employers have recognized critical thinking as an increasingly important outcome of a college education [1].
Critical thinking considered as an important topic for $21^{\text {st }}$ century teaching and learning, it is one of the factors contributing to the success of the individuals [2]. In education, there is a great movement in the development of critical thinking, creative thinking, collaboration, and communication skills abbreviated with 4Cs [3]. The tendency to improve and develop thinking skills in mathematics education [4], especially critical thinking skills [5] very needed. The Government of Indonesia recommends that graduates of primary and secondary education programs are required to have creative thinking skills, productive, independent, critical, collaborative, and communicative [6]. Based on this, all of the basic and intermediate educational institutions in Indonesia are required to develop these skills.

Critical thinking is at the heart of the future for every society in the world [7]. Gaining the ability of critical thinking will help individuals to define the aims of his or her life [8]. Critical thinking is a necessary thought especially in education [9], because it is widely recognized as an essential component of education and a powerful and vital resource in one's personal and civic life [10]. Critical thinking is a metacognition process consisting of a number of sub-capabilities and dispositions [11]. Critical thinking was frequently referred to as the individuals' cognitive ability to think and make correct decisions independently, and utilizing rational/logical thought [12], [13].

Critical Thinking has two dimensions; the first dimension is critical thinking skills and the second dimension is disposition to think critically [14], [15]. The critical thinking skills cannot be separated from the disposition of critical thinking. To think critically required the disposition/attitude of critical thinking [16]. The disposition of thinking is their tendency to guess, ask, seek clarity, risk intellect, and think critically and imaginatively [17]. Without the habit to tend to think critically, students will not use their critical thinking [18]. Critical thinking disposition is considered as complementary to critical thinking skills and habits [19]. The components of critical thinking disposition are truth-seeking, open-mindedness, analyticity, systematicity, self-confidence, inquisitiveness and maturity [14], [20]-[22]. Of the seven components, 
there are several components that need to be studied more deeply, are analyticity and systematicity. Because, in fact, the prospective student's analyticity is still low [23] and student systematicity needs to be improved [24]. The research by [21] shows where the scores for open-mindedness, inquisitiveness, and maturity were higher than those of truth-seeking, analyticity, systematicity, and self-confidence. In addition, the results of research conducted by [14], analytical, systematicity and open-mindedness components have the lower value than self-confidence and inquisitiveness components. The analytical person solves the problem by re-examining the parts of the answers as a whole, taking into account the influence of his choice of answers to others, and having a good argument, whereas the systematic person tends to be more organized, orderly, focused and diligent in doing the work/problems [22]. Analyticity measures how one's reasoning emerges and how to anticipate potential difficulties in solving problems. Systematize measures organizing, sorting, focusing and finding diligently [25].

There are limited of critical thinking disposition's research, so its need for research on the disposition of critical thinking [1]. Past studies on critical thinking disposition were largely cross-sectional and did not take into account important background variables. Other research on critical thinking disposition examined the relationship between professional values and critical thinking disposition of Science-technology and mathematics teachers. However, there did not explain the critical thinking disposition of the teachers clearly. The disposition of critical thinking of mathematics teachers and science technology is still low [19].

The purpose of this study is to describe the disposition of critical thinking on the analyticity and systematicity components of first-year college students in mathematics education major when solving non-routine problems. Responses to the following questions have been sought to achieve this purpose:

1. How the process of first-year college students in mathematics education major when solving non-routine problems?

2. How the analyticity of first-year college students in mathematics education major when solving non-routine problems?

3. How the systematicity of first-year college students in mathematics education major when solving non-routine problems?

\section{Methods}

This research is qualitative descriptive research and the subjects are first-year college students in mathematics education major at Universitas PGRI Madiun, Indonesia. The subjects were collecting with purposive sampling technique. The criteria of subjects are first-year college students can solve the mathematics problem using critical thinking. There are 55 first-year college students in mathematics education major, however, the students were meet the criteria 20 students only.

The instruments used are 3 math problems consisting of non-logical and incomplete questions. A teaching strategy that involves non-routine problems in the classroom will develop high-level thinking skills in the process of understanding, exploring, and applying mathematical concepts [26]. The technique used in the determination of the subject is the method of purposive sampling (taking the subject by choosing without random with a particular purpose).

There are five stages in this study. First, giving non routine questions to all subjects and asking each subject to do it. The problems provided consist of 3 (three) non-routine problems, there are one incomplete problem and 2 (two) non-logical problems. The non-routine problems used in this study are

(1) Find the value of a, b, c where $a, b, c \in A=\{1,3,5,7$, $9,11,13,15\}$ and you can make a repetition of the number such that $\mathrm{a}+\mathrm{b}+\mathrm{c}=30$ !

(2) If $0<\mathrm{a}<\mathrm{b}$, a $2+\mathrm{b} 2=-4 \mathrm{ab}$, then find the value of $(b-a) /(a+b)$ !

(3) Find the invers of the function $f(x)=x^{2}$ !

The second stage, observing and recording video, researchers recorded directly each subject and also by recording directly any activity of research subjects when solving non-routine problems based on the observation sheet to classify the tendency of analyticity and systematicity. Observations focused on behavioral trends in performing analyticity and systematicity during non-routine tasks.

The third stage, analyzing the two components of critical thinking disposition that appear on each subject of research based on the results of direct observation and video recording, that are analyticity and systematicity. The results were analyzed in the form of conclusions about the behavior of research subjects whether the subject to do analyticity and systematicity or not. Fourth, perform triangulation of data to confirm the results of the analysis is the conclusion whether the subject to do analyticity and systematicity or not by conducting an in-depth interview. Interview guidelines used are with a structured and open format. In addition to interviews, there is also a data reduction stage that is not required after in-depth interviews. Finally, summarizes the results of the analysis of two components of critical thinking disposition of prospective mathematics teachers based on the results of observation, video recording, and interviews so that data can be obtained by a disposition of critical thinking of the students of mathematics education in solving the non-routine problem. The results obtained at the last stage are the classification of analyticity and systematicity of prospective mathematics teachers when solving non-routine questions. The indicator of analyticity and systematicity when solving the non-routine problem can be viewed on Table 1 below: 
Table 1. The Indicator of Analyticity and Systematicity when solving the nonroutine problem

\begin{tabular}{|c|c|c|}
\hline $\begin{array}{l}\text { Critical thinking } \\
\text { disposition }\end{array}$ & Nonlogic problems & Incomplete problems \\
\hline Analyticity & $\begin{array}{l}\text { - } \quad \text { Can analyzing the problems } \\
\text { - } \quad \text { Doing the reflective and checking the solution } \\
\text { - } \quad \text { Being able to find a non-logic of the problem and } \\
\text { turn it into a logical question }\end{array}$ & $\begin{array}{l}\text { - } \quad \text { Can analyzing the problems } \\
\text { - } \quad \text { Doing the reflective and checking the solution } \\
\text { Can find the incomplete of problem and turn } \\
\text { them into complete problems }\end{array}$ \\
\hline Systematicity & $\begin{array}{l}\text { - Write down answers that are well organized } \\
\text { - } \quad \text { ordered, focused and diligent in the work }\end{array}$ & $\begin{array}{l}\text { - Write down answers that are well organized, } \\
\text { - } \quad \text { ordered, focused and diligent in the work }\end{array}$ \\
\hline
\end{tabular}

\section{Result}

The results showed that the students have not yet critical thinking. Of the 20 students there are 4 students who show the existence of symptoms of disposition of critical thinking, namely $\mathrm{T}, \mathrm{Y}, \mathrm{K}$ and $\mathrm{R}$. They can find the non-logic of the problem and describe it. Of the four students only one student who can change the problem becomes a logical matter. In question number 1 , subject $T$ tries to add 3 numbers directly, and after 8 attempts and the result fails. Here $\mathrm{T}$ is diligent in doing but still lacking focus in understanding the problem. $\mathrm{T}$ is able to analyze the problem and find the insanity of the problem, he also turns the matter into a logical question by giving a statement that the set A must have even member numbers. The answer of subject $\mathrm{T}$ can be viewed on Figure 1 below:

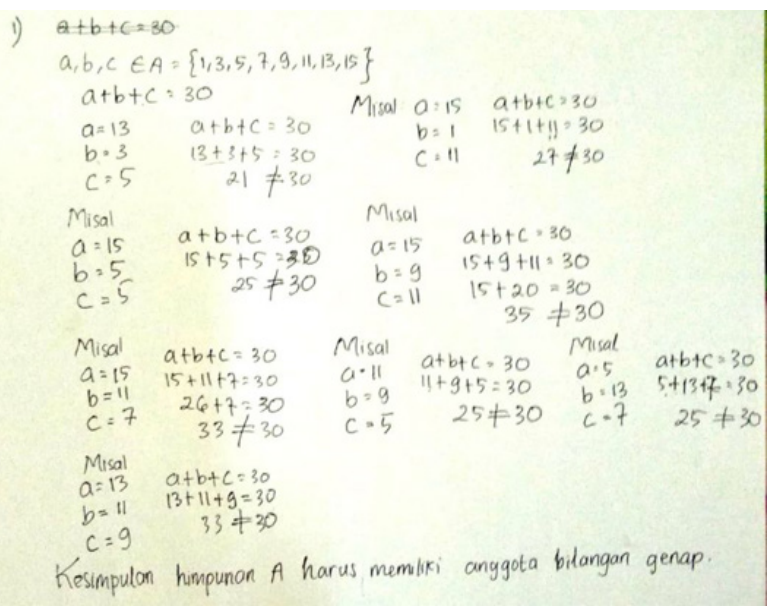

Figure 1. The Answer of Subject $T$ number 1
Subject $\mathrm{Y}$ is experimented by determining 2 numbers first then looking for the third number by subtracting 30 with the sum of two numbers that have been determined. Then realize that the number that in can not be a member of set $\mathrm{A}$, try it is done 7 times. Subjects do analysis. $\mathrm{Y}$ can find the insignificance of the problem but can not change the problem to be a logical matter. The answer is less well organized, still lacking focus because it should be 3 times trying to be able to conclude. Subject $\mathrm{R}$ examines the problem, and analyzes first, the student is immediately able to detect a non-logic on the matter. The analysis is done by recalling the even and odd number characteristics. That is where the mismatch arises with facts, namely number 30 , the subject says the result should not be an even number but an odd number, because odd plus odd number of even and even odd is the result is odd. The subject gives the conclusion that there is no triple member number of set $\mathrm{A}$ that satisfies the equation $\mathrm{a}+\mathrm{b}+\mathrm{c}=30$. The subject has not changed the matter to be a logical matter, only knowing the problem is not logical. And give one counter example. Subject $\mathrm{K}$ determines the value of a first, by making a list of 8 columns with a value of each of all members of set A. The first value of $A$ is 15 , the subject analyzes by thinking 15 summed with the other members, so as not to find the result 30 . And so on and on. The answer is well organized, the subject of focus but does not give the right analysis, the subject also does not change the matter to be a logical matter. After interviewing the subject said that the three odd numbers if summed the result is also an odd number, not even an even number. The conclusion given there is no value of $a, b$, c fulfilling. 


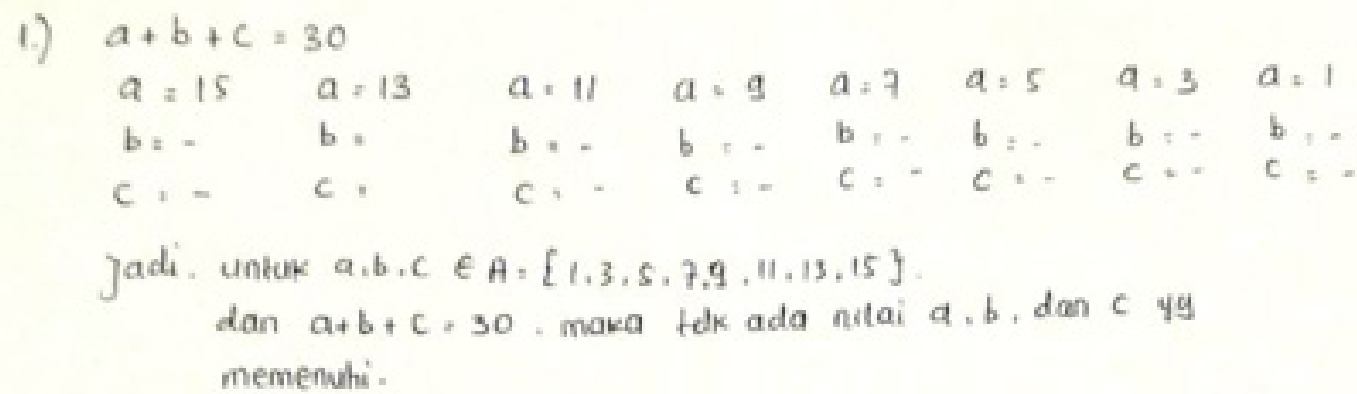

Figure 2. The Answer of Subject K number 1

In question number 2, Subject $\mathrm{T}$ tries 3 times, more focused than before. Have done the analysis and found the non-logical. Already changing the matter to a logical problem but not writing how the relationship a and $b$, just write a must have a negative. It means either one of $a$ or $b$ must be negative. Subject $Y$ tried to change the equation of questions, but did not work out. Then do experiment by substituting the values of $a$ and $b$, by direct path takes 2 numbers not explained where $a$ and mana $b$ (less organized), just tried 2 times (more focused). Finding the insanity of the problem (from video recording) but not yet changing the matter becomes a logical matter. Subject $\mathrm{R}$ does not do problem number 2 because do not understand the material. The subject of $\mathrm{K}$ does a straightforward question without looking at the truth of the matter, with the algebra of the cluster. Until the end is not settled, the subject is completely unaware of any incoherence in the matter.

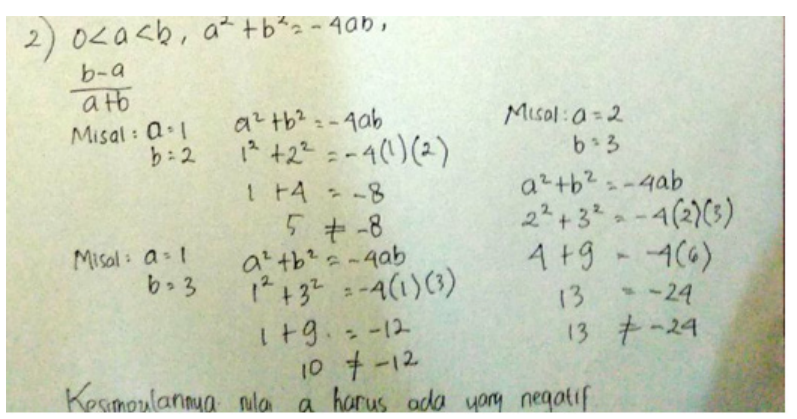

Figure 3. The answer Subject $\mathrm{T}$ number 2

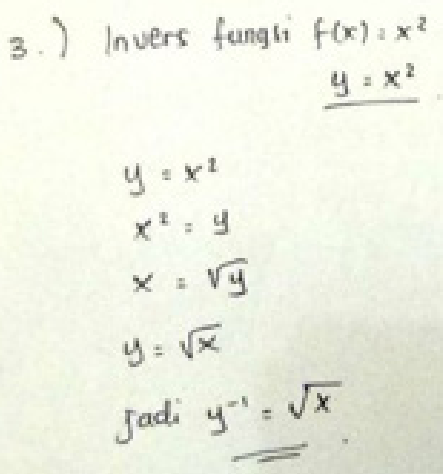

Figure 4. The Answer of Subject K number 3
In question no 3 , subject $\mathrm{T}$ does not work at all, while the subject $\mathrm{Y}$ does procedural without realizing that the problem is incomplete, not understanding the meaning of $\mathrm{x}$. not checking back answers. Subject $\mathrm{R}$ did not know the incompleteness of the problem. Subjects do procedurally and make mistakes in working. The subject does not yet understand the true function of the inverse. Subject $\mathrm{K}$ does procedurally and gets settled, but the settlement only applies to $\mathrm{x}$ members of real numbers. According to the interview the subject says $\mathrm{x}$ is a real number.

\section{Discussion}

Based on the results obtained, it can be said that the disposition of critical thinking on the component of analyticity and systematicity of students of mathematics education program when solving non routine problems is still low. There are some unanswered questions, the analyticity is still low, they have not done the analysis of the problem and the answer well, have done a little process of checking the answer and have been able to find the incomplete/incompleteness of the problem, but not all of them can change the problem is not logical/incomplete matter that is logical/complete. Student candidates for mathematics teacher also have not written a well-organized, ordered, focused and diligent answer in doing. They tend to be hasty and write out un-systematic answers that are hard to understand. The results are in accordance with the results made by [3] which state that the prospective math teacher in Indonesia is not critical thinking because it is at the level of non-critical thinkers.

This is very contrary to opinion [20] which states that a person who thinks critically always has the characteristics of critical thinkers who always demand accuracy and analyze and assess what to do. In this study, students of mathematics teacher candidate tend not to check the truth about the problem before doing and do not do analysis based on logical proof and argumentation. Thus, the analyticity and systematicity of a mathematics student candidate when solving non-routine questions is not able to change the views and positive opinions of each given problem.

Based on the discussion, it is necessary to do the learning 
that focuses on the development of critical thinking disposition of prospective mathematics teacher students, especially analyticity and systematicity so that the prospective mathematics teacher becomes a critical thinker. There are several ways that can be done to develop a critical thinking disposition that is by learning explicit (infusion) and implicit (immersion) and a combination of both [27]-[29]. It also can be applied learning that focuses on problem solving with the provisions of non-routine problems as well as traditional learning methods [30].

\section{Conclusions}

When solving non-routine problems first-year college students do trial and error by experimenting with all numbers and forgetting mathematical concepts. They did not find irregularities in the problems and immediately worked without analyzing the problems first. They are aware of the oddity of the problem when working on it and they are confused.

Analyticity and systematicity of mathematics education students when solving non-routine problems are still low. They have not done the analysis of the problem and the answer well, have done a little process of checking the answer and have been able to find the incomplete/ incompleteness of the problem, but not all of them can change the problem is not logical/incomplete matter that is logical/complete. First-year college students also have not written a well-organized, ordered, focused and diligent answer in doing. They tend to be hasty and write out un-systematic answers that are hard to understand.

The suggestion given is to apply continuous learning mathematics that focuses on developing critical thinking disposition especially analyticity and systematicity by applying infuse learning, immersion, combined infusion and immersion, and problem solving. It can also be done habitually giving non-routine questions in every learning mathematics.

\section{REFERENCES}

[1] R. H. Stupnisky, R. D. Renaud, L. M. Daniels, T. L. Haynes, and R. P. Perry, "The Interrelation of First-Year College Students ' Critical Thinking Disposition, Perceived Academic Control, and Academic Achievement Published by: Springer of First-Year College Students ' Critical Thinking Disposition, Perceived Academic Control ," Res. High. Educ., vol. 49, no. 6, pp. 513-530, 2008.

[2] D. I. Ekici, "The Effects of Online Communities of Practice on Pre-Service Teachers ' Critical Thinking Dispositions," EURASIA J. Math. Sci. Technol. Educ., vol. 13, no. 7, pp. 3801-3827, 2017.

[3] A. R. As'ari, A. Mahmudi, and E. Nuerlaelah, "Our Prospective Mathematic Teachers Are Not Critical
Thinkers Yet," J. Math. Educ., vol. 8, no. 2, pp. 145-156, 2017.

[4] V. R. Jacobs, M. L. Franke, T. P. Carpenter, L. Levi, and D. Battey, "Professional development focused on children's algebraic reasoning in elementary cchool," J. Res. Math. Educ., vol. 38, no. 3, pp. 258-288, 2007.

[5] S. Maričića and K. Špijunovićb, "Developing Critical Thinking in Elementary Mathematics Education through a Suitable Selection of Content and Overall Student Performance," Procedia - Soc. Behav. Sci., vol. 180, no. November 2014, pp. 653-659, 2015.

[6] Permendikbud, Peraturan Menteri Pendidikan dan Kebudayaan Nomor 20 Tahun 2016 tentang Standar Kompetensi Lulusan Pendidikan Dasar dan Menengah. 2016.

[7] D. Ben-chaim, S. Ron, and U. Zoller, "The Disposition of Eleventh-Grade Science Students Toward Critical Thinking," Sci. Educ., vol. 9, no. 2, pp. 149-159, 2000.

[8] H. Turan, "Comparison of critical thinking dispositions of prospective teachers," Educ. Res. Rev., vol. 11, no. 8, pp. 867-876, 2016.

[9] S. Maharani and E. Suprapto, "Developing group investigation-based book on numerical analysis to increase critical thinking student' $\mathrm{s}$ ability Developing group investigation-based book on numerical analysis to increase critical thinking student' s ability," J. Phys. Conf. Ser., vol. 983, pp. 1-5, 2018.

[10] C. A. Giancarlo, S. W. Blohm, and T. Urdan, "Educational and Psychological Measurement," Educ. Psychol. Meas., vol. 64, no. 2, pp. 347-364, 2004.

[11] C. P. Dwyer, M. J. Hogan, O. M. Harney, and C. Kavanagh, "Facilitating a student-educator conceptual model of dispositions towards critical thinking through interactive management," Educ. Tecnol. Res., vol. 65, pp. 47-73, 2017.

[12] S. Shirkhani and M. Fahim, "1st International Conference on Foreign Language Teaching and Applied Linguistics Enhancing critical thinking in foreign language learners 1st International Conference on Foreign Language Teaching and Applied Linguistics May 5-7 2011 Sarajevo," in 1st International Conference on Foreign Language Teaching and Applied Linguistics, 2011, pp. 2000-2004.

[13] P. H. Harasym, T. Tsai, and P. Hemmati, "Current Trends in Developing Medical Studnets' Critical Thinking Abilities," Kaohsiung J. Med. Sci., vol. 24, no. 7, pp. 341-355, 2008.

[14] A. S. Mahmoud and H. A. Mohamed, "International Journal of Nursing Sciences Critical Thinking Disposition among Nurses Working in Puplic Hospitals at Port-Said Governorate," Int. J. Nurs. Sci., vol. 4, no. 2, pp. 128-134, 2017.

[15] E. T. Pascarella and P. T. Terenzini, "How college affects students: A third decade of research.," How College Affects Students: A Third Decade of Research. pp. 534-545, 2005.

[16] D. F. Halpern, "Teaching for Critical Thinking: Helping College Students Develop the Skills and Dispositions of a Critical Thinker," in New Directions for Teaching and Learning, no. 80, 1999, pp. 69-74.

[17] S. Tishman, E. Jay, D. N. Perkins, S. Tishman, and D. N. 
Perkins, "Teaching Thinking Dispositions: From Transmission to Enculturation," Theory Pract., vol. 32, no. 3, pp. 147-153, 1993.

[18] M. Moradi and M. Kouroshnia, "The moderating role of locus of control in the relationship between dimension of family communication patterns and criticawl thinking disposition of high school students," Indian J. Posit. Psychol., vol. 7, no. 4, pp. 405-409, 2016.

[19] S. A. Sahin, N. Tunca, Y. Altinkurt, and K. Yilmaz, "Relationship between professional values and critical thinking disposition of science-technology and mathematics teachers," Eurasia J. Math. Sci. Technol. Educ., vol. 12, no. 1, pp. 25-40, 2016.

[20] R. H. Ennis, The Nature of Critical Thinking: An Outline of Critical Thinking Dispositions and Abilities. Cambridge: MA, 2011.

[21] C. Zhang et al., "The Effects of Reflective Training on the Disposition of Critical Thinking for Nursing Students in China : A Controlled Trial," Asian Nurs. Res. (Korean. Soc. Nurs. Sci)., vol. 11, no. 3, pp. 194-200, 2017.

[22] B. A. Wilson, "Bussiness Administration Students , Disposition Toward Critical Thinking," J. Gen. Educ., vol. 47, no. 4, pp. 304-326, 1998.

[23] Z. Özsoy-Güneş, İ. Güneş, Y. Derelioğlu, and F. G. Kırbaşlar, "The Reflection of Critical Thinking Dispositions on Operational Chemistry and Physics Problems Solving of Engineering Faculty Students," Procedia - Soc. Behav. Sci., vol. 174, no. February, pp. 448-456, 2015.

[24] N. Lampert, "Critical Thinking Dispositions as A Outcome of Undergraduate Education," J. Gen. Educ., vol. 56, no. 1, pp. 17-33, 2007.

[25] R. O. N. E. Mcbride, P. Xiang, D. Wittenburg, and J. Shen, "An Analysis of Preservice Teachers ' Dispositions Toward Critical Thinking: a cross-cultural perspective," Asia-Pacific J. Teach. Educ., vol. 30, no. 2, pp. 131-140, 2002.

[26] A. H. Abdullah, N. L. Z. Abidin, and M. Ali, "Analysis of students' errors in solving Higher Order Thinking Skills (HOTS) problems for the topic of fraction," Asian Soc. Sci., vol. 11, no. 21, pp. 133-142, 2015.

[27] E. Aizikovitsh-udi and D. Cheng, "Developing Critical Thinking Skills from Dispositions to Abilities: Mathematics Education from Early Childhood to High," Creat. Educ., vol. 6, no. March, pp. 455-462, 2015.

[28] Z. Arsal, "The Effects of Microteaching on the Critical Thinking Dispositions of Pre-service Teachers," Aust. J. Teach. Educ., vol. 40, no. 40, 2015.

[29] N. Mohd Darby and A. Mat Rashid, "Critical Thinking Disposition: The Effects of Infusion Approach in Engineering Drawing," J. Educ. Learn., vol. 6, no. 3, p. 305, 2017.

[30] S. Temel, "The effects of problem-based learning on pre-service teachers' critical thinking dispositions and perceptions of problem-solving ability.," South African J. Educ., vol. 34, no. 1, pp. 1-20, 2014. 